\title{
Environmental Gamma Dose Evaluation During Explosive Materials Analysis by PGNAA Technique Using MCNPX Code
}

\author{
M.N. NASRABADI*, S. OMIDI \\ Department of Nuclear Engineering, Faculty of Advanced Sciences \& Technologies, University of Isfahan, \\ Hezarjerib Street, 81746-73441, Isfahan, Iran
}

\begin{abstract}
Increased use of radiation in medicine, industry, and laboratories, requires safe conditions to be provided for its optimal use. One of the cases in which people are exposed to radiation, is during the detection of explosive materials by PGNAA method. Therefore, external dosimetry is necessary for workplaces where the method is used. In this study, Monte Carlo simulation program, MCNPX has been used to simulate gamma dose in the environment during the detection of explosive materials by PGNAA method. The simulated results were validated practically. The results indicate a good agreement between the simulated and measured data. The study demonstrated that MCNPX code can be used effectively for simulating gamma dose in various environments.
\end{abstract}

DOI: $10.12693 /$ APhysPolA.127.961

PACS: 87.52.- $\mathrm{g}, 61.80 .-\mathrm{x}, 78.70 .-\mathrm{g}$

\section{Introduction}

Gamma rays, radioactive nuclides, and fissionable materials are widely used in the medicine, industry, research, and energy production. In spite of these benefits, people are exposed while providing and using these radioactive sources. Since any radiation exposure may have unexpected risks for people, determining the radiation dose is of crucial importance. In prompt gamma neutron activation analysis (PGNAA) method, mixed neutron-gamma fields are generated by radiation sources. The method is based upon bombarding a sample with neutrons and measuring the prompt gamma spectrum emitted from the elements within the sample after absorbing the neutrons [1]. The energies of the gamma rays are characteristic of the element's isotopes, and their intensities are proportional to their concentration $[2,3]$. PGNAA is a non-destructive method for detection of materials, with numerous advantages and applications in different areas of archaeological studies, coal and oil industry, medical application, detection of explosive materials, and various narcotics [4-7]. Exposure to radiation during the use of PGNAA method for the detection of explosives, has been considered for this research. Many studies have been devoted to detection of landmines, including anti tank and personal landmines and inspection of airline baggage's cargo [8-12]. The purpose of this research is to measure the gamma dose in laboratory conditions during the determination of nitrogen concentration using PGNAA method and comparing the experiment with the MCNPX simulated results. Determination of gamma dose in this work enables us to design suitable shields, for cases where PGNAA method is used for detecting explosive materials.

*corresponding author; e-mail: mnnasrabadi@ast.ui.ac.ir

\section{Simulation}

MCNPX version 2.4 software was applied for simulation of the interaction of gamma and neutron with materials as well as for calculation of their doses in every point [13]. Library cross sections ENDF/B-VI was used in MCNPX software. MCNPX code is useful for PGNAA experiments and dosimetry simulations. To measure dose, F5 tally with DE5 and DF5 tally was used. DE5 and DF5 tallies use dose conversion coefficients to convert flux to dose. Hence, with using these tallies, dose can be estimated everywhere. Furthermore, it is possible to determine the dose in different units such as $(\mathrm{rem} / \mathrm{h}) /\left(\right.$ particles $\left./ \mathrm{cm}^{2} \mathrm{sec}\right)$ or $(\mathrm{Sv} / \mathrm{h}) /\left(\right.$ particles $\left./ \mathrm{cm}^{2} \mathrm{sec}\right)$. In this work, dose was measured in $(\mathrm{Sv} / \mathrm{h}) /\left(\right.$ particles $\left./ \mathrm{cm}^{2} \mathrm{sec}\right)$ unit and standard dose function of ICRP-21 1971 was used. The dimensions and distances of devices in the laboratory were exactly simulated by the code, so the geometry of the PGNAA setup was exactly simulated, similar to the experimental PGNAA setup. The runtime of simulating was 20 minutes. The source was simulated as a Watt fission spectrum. In the main work, for determination of nitrogen concentration in explosive materials, two NaI detectors were used to obtain gamma spectrum, which is indicated in Fig. 1. The detector used for dose calculation was an Inspector + dosimeter operated in dose rate mode with the effective diameter of $45 \mathrm{~mm}$. The Inspector+ is a healthy and safe instrument that is optimized to detect low levels of radiation.

\section{Experiment}

At first, a point was chosen as an origin, and the other points were considered before it. All sample vessels with $100,300,500 \mathrm{~g}$ of melamine in them were placed at the origin point. Water container and the source were placed on the suitable stool, on the vessel. The top of the sample vessel was in contact with the bottom of the con- 
tainer. Schematic diagram of the system is shown in Fig. 1. Before transferring the neutron source to the central tube of the container, the background gamma dose $(0.12 \mu \mathrm{Sv} / \mathrm{h})$ was measured. Then each sample was irradiated for an hour. Irradiation by thermal neutrons was also performed without a sample, for an hour.

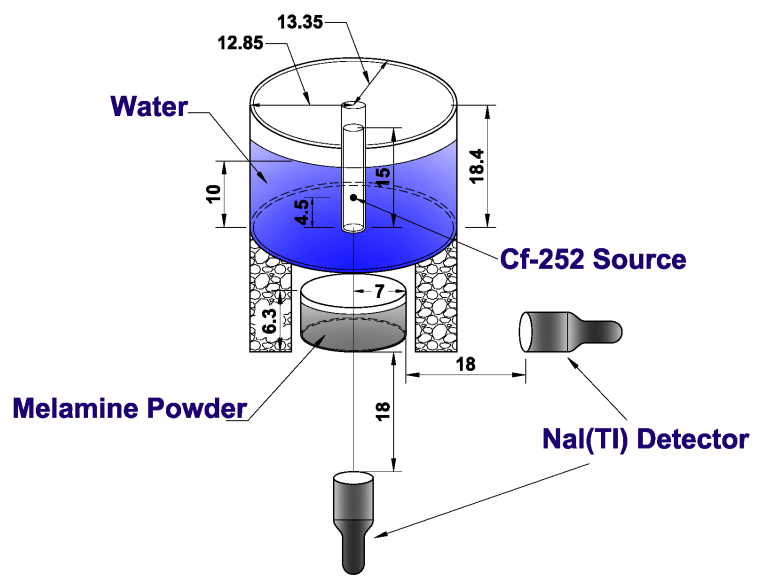

Fig. 1. Experimental setup.

In the work, ${ }^{252} \mathrm{Cf}$ source $\left(2.65 \mathrm{y}, 6.67 \times 10^{6} \mathrm{n} / \mathrm{cm}^{2} \mathrm{~s}\right)$, a natural fissionable source having an energy spectrum between 1 to $14 \mathrm{MeV}$ and average energy of $2.35 \mathrm{MeV}$, was chosen as a suitable source. Therefore, this source was located within the distance of $4.5 \mathrm{~cm}$ from the bottom of the polyethylene cylinder with the height of $15 \mathrm{~cm}$ and the radius of $3 \mathrm{~cm}$. Then this cylinder was placed inside a water container. In order to thermalize the neutrons, a plastic container with $12.85 \mathrm{~cm}$ radius and $18.4 \mathrm{~cm}$ height was used. A cylindrical tube made of polyethylene, with the thickness of $2 \mathrm{~mm}$, the radius of $1.7 \mathrm{~cm}$, and the height of $14 \mathrm{~cm}$, was stuck in the middle of container's surface. Then water was poured into the container, around the tube, up to the level of $10 \mathrm{~cm}$. The source was put inside the tube, in the middle of the container. Consequently, the fast neutrons from ${ }^{252} \mathrm{Cf}$ source were isotropically thermalized. The optimum amount of water to achieve maximum thermal neutron flux was calculated with MCNP code.

In addition to explosive materials, there are other innocuous materials having a great amount of nitrogen in their structures [9], such as melamine $\left(\mathrm{C}_{3} \mathrm{H}_{6} \mathrm{~N}_{6}\right)$, silk $\left(\mathrm{C}_{3} \mathrm{H}_{11} \mathrm{O}_{6} \mathrm{~N}_{3}\right)$ and chemical fertilizer. In this study, because of safety issues we decided to replace explosive materials with a safer material. Explosive materials have high nitrogen content and can be detected using nuclear based explosive detection methods, which can detect explosives by identifying their elemental components, especially nitrogen. Then, since melamine also has high nitrogen content we chose melamine for this study and we believe that melamine could be an appropriate selection for explosive materials, within the goals of our study. Melamine is a white powder with the $\mathrm{C}_{3} \mathrm{H}_{6} \mathrm{~N}_{6}$ chemical formula, $1.57 \mathrm{~g} / \mathrm{cm}^{3}$ density and $99.80 \%$ purity. The sample vessel was a cylinder with $7 \mathrm{~cm}$ radius, height of $6.3 \mathrm{~cm}$ and thickness of $2 \mathrm{~mm}$. The sample vessel is made of polyethylene with the density of $0.97 \mathrm{~g} / \mathrm{cm}^{3}$.

\section{Results and discussion}

The dosimeters were placed at the previously specified points. Considering the points' coordinates and their distances, gamma doses were obtained once in the presence of the samples with three different masses of 100, 300 and $500 \mathrm{~g}$ of melamine, and then in the absence of the samples. The results are illustrated in Table I. Lower gamma doses are expected when the distance from the source is increased, but higher material mass should increase the gamma doses. The doses calculated by MCNPX code for the same positions are reported in Table II.

Experimental gamma doses for four different amounts of melamine in $\mu \mathrm{Sv} / \mathrm{h}$.

TABLE I

\begin{tabular}{c|c|c|c|c|c}
\hline \hline$(\mathrm{x}, \mathrm{y}, \mathrm{z})$ & $\mathrm{R}[\mathrm{cm}]$ & $0 \mathrm{~g}$ & $100 \mathrm{~g}$ & $300 \mathrm{~g}$ & $500 \mathrm{~g}$ \\
\hline$(13.35,23.35,0)$ & 26.90 & 3.63 & 3.82 & 3.95 & 4.09 \\
\hline$(13.35,33.35,0)$ & 35.92 & 2.08 & 2.23 & 2.39 & 2.47 \\
\hline$(-23.35,33.35,0)$ & 40.71 & 1.62 & 1.65 & 1.68 & 1.81 \\
\hline$(13.35,43.35,0)$ & 45.36 & 1.21 & 1.34 & 1.36 & 1.56 \\
\hline$(13.35,-70.35,0)$ & 71.61 & 0.52 & 0.55 & 0.58 & 0.60
\end{tabular}

TABLE II Calculated gamma doses for four different amounts of melamine in $\left(\times 10^{-7} \mu \mathrm{Sv} / \mathrm{h}\right) /\left(\right.$ particles $\left./ \mathrm{cm}^{2} \mathrm{~s}\right)$.

\begin{tabular}{c|c|c|c|c|c}
\hline \hline$(\mathrm{x}, \mathrm{y}, \mathrm{z})$ & $\mathrm{R}[\mathrm{cm}]$ & $0 \mathrm{~g}$ & $100 \mathrm{~g}$ & $300 \mathrm{~g}$ & $500 \mathrm{~g}$ \\
\hline$(13.35,23.35,0)$ & 26.90 & 5.71 & 5.85 & 6.02 & 6.12 \\
\hline$(13.35,33.35,0)$ & 35.92 & 3.13 & 3.19 & 3.33 & 3.37 \\
\hline$(-23.35,33.35,0)$ & 40.71 & 2.44 & 2.48 & 2.54 & 2.59 \\
\hline$(13.35,43.35,0)$ & 45.36 & 1.98 & 1.99 & 2.06 & 2.11 \\
\hline$(13.35,-70.35,0)$ & 71.61 & 0.796 & 0.809 & 0.831 & 0.848
\end{tabular}

In order to compare the calculated and the experimental doses, they were evaluated relative to gamma dose rate at a specific point, as is demonstrated in Tables III and IV. Figures $2-5$ show relative doses versus distance for every sample.

The relative errors ( $\mathrm{RE}$ ) for the calculated and experimental doses are reported. The dose at any point was calculated relative to the dose rate at the point $(-23.35$, $33.35,0)$.

TABLE III

Experimental and calculated gamma doses relative to the dose rate at $(-23.35,33.35$, $0)$ in the absence of melamine.

\begin{tabular}{c|c|c|c}
\hline \hline $\mathrm{R}[\mathrm{cm}]$ & Exp. & Cal. & $\mathrm{RE}$ \\
\hline 26.90 & 2.23430 & 2.34003 & 0.04732 \\
\hline 35.92 & 1.28165 & 1.28235 & 0.00055 \\
\hline 40.71 & 1.00000 & 1.00000 & 0.00000 \\
\hline 45.36 & 0.74631 & 0.81229 & 0.08841 \\
\hline 71.61 & 0.32194 & 0.32616 & 0.01310
\end{tabular}

Since MCNPX code calculates dose rates per particle, the results should be converted to absolute dose rate $(\mu \mathrm{Sv} / \mathrm{h})$, using the known incident neutron flux. 


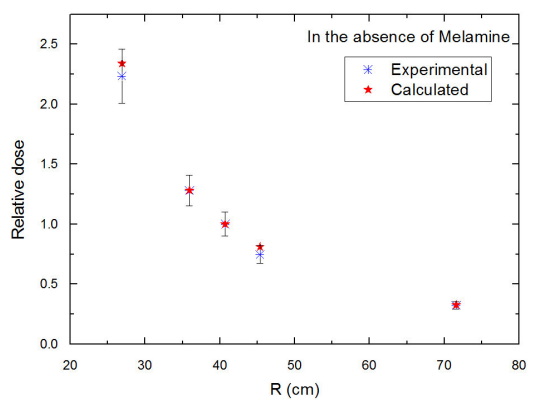

Fig. 2. Experimental and calculated gamma dose relative to the dose rate at $(-23.35,33.35,0)$ in the absence of melamine.

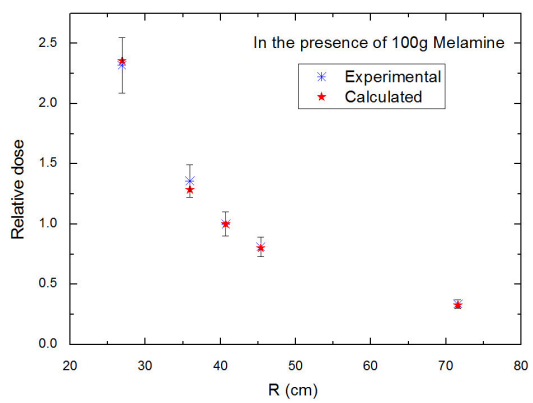

Fig. 3. Experimental and calculated gamma dose relative to the dose rate at $(-23.35,33.35,0)$ for $100 \mathrm{~g}$ melamine.

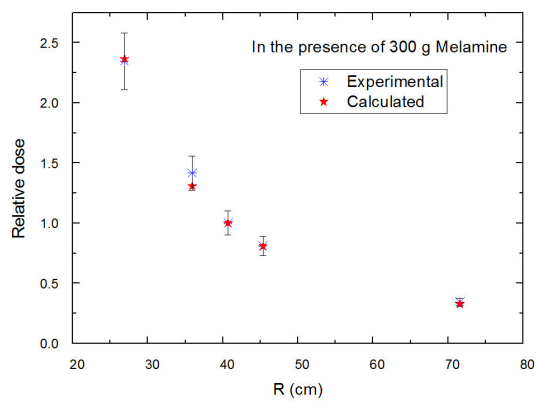

Fig. 4. Experimental and calculated gamma dose relative to the dose rate at $(-23.35,33.35,0)$ for $300 \mathrm{~g}$ melamine.

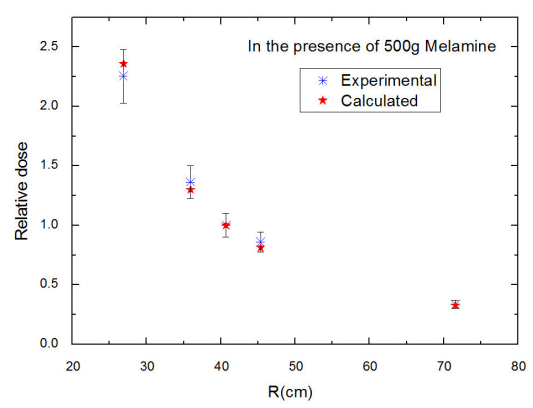

Fig. 5. Experimental and calculated gamma dose relative to the dose rate at $(-23.35,33.35,0)$ for $500 \mathrm{~g}$ melamine.
TABLE V

Comparison of experimental and calculated absolute dose rates in $\mu \mathrm{Sv} / \mathrm{h}$ in the absence of melamine.

\begin{tabular}{c|c|c|c}
\hline \hline R $[\mathrm{cm}]$ & Exp. & Cal. & RE \\
\hline 26.90 & $3.6285 \pm 0.36285$ & $3.8108 \pm 0.0146$ & 0.0502 \\
\hline 35.92 & $2.0814 \pm 0.20814$ & $2.0884 \pm 0.0137$ & 0.0033 \\
\hline 40.71 & $1.6240 \pm 0.16240$ & $1.6285 \pm 0.0131$ & 0.0028 \\
\hline 45.36 & $1.2120 \pm 0.12120$ & $1.3228 \pm 0.0127$ & 0.0915 \\
\hline 71.61 & $0.5228 \pm 0.05228$ & $0.5312 \pm 0.0127$ & 0.0159
\end{tabular}

The absolute dose rates are calculated by the code and the relative errors between experimental and calculated absolute doses are reported in Tables V and VI. A good agreement was found between experimental and calculated results.

\section{Conclusion}

Considering the obtained results, shown in the figures, the experimental doses are in good agreement with the doses calculated by MCNPX code. The relative errors are less than $10 \%$. Hence, the calculated data obtained by MCNPX code are validated, and it is possible to calculate gamma dose with any arbitrary explosive material and for any dimension of the sample vessel. By increasing the distances, the gamma dose was decreased. As indicated in the text, even in the absence of sample, there is a background dose. Comparing the results for a certain point, it was considered that by increasing the sample mass, the gamma dose was increased too. Also considering the obtained doses for different distances and comparing them with the average annual dose, which is recommended by the ICRP commission, it can be concluded that the amount of obtained doses during working with explosive materials is significant and therefore using suitable shields is necessary.

\section{References}

[1] M.N. Nasrabadi, F. Bakhshi, M. Jalali, A. Mohammadi, Nucl. Instrum. Methods A 659, 378 (2011).

[2] A.G.C. Nair, K. Sudarshan, N. Raje, A.V.R. Reddy, S.B. Manohar, A. Goswami, Nucl. Instrum. Methods A 516, 143 (2004).

[3] W.V. Nunes, A.X. da Silva, V.R. Crispim, R. Schirru, Appl. Radiat. Isot. 56, 937 (2002).

[4] H.J. Im, B.C. Song, Y.J. Park, K. Song, Appl. Radiat. Is ot. 67, 1458 (2009)

[5] D.L. Chichester, E. Empey, Appl. Radiat. Isot. 60, 55 (2004).

[6] B. Király, T. Sanami, R. Doczi, J. Csikai, Nucl. Instrum. Methods B 213, 452 (2004).

[7] M.N. Nasrabadi, M. Jalali, A. Mohammadi, Nucl. Instrum. Methods B 263, 473 (2007).

[8] E.T.H. Clifford, J.E. McFee, H. Ing, H.R. Andrews, D. Tennant, E. Harper, A.A. Faust, Nucl. Instrum. Methods A 579, 418 (2007).

[9] H.J. Im, H.J. Cho, B.C. Song, Y.J. Park, Y.S. Chung, W.H. Kim, Nucl. Instrum. Methods A 566, 442 (2006). 
Experimental and calculated gamma doses relative to

TABLE IV the dose rate at $(-23.35,33.35,0)$.

\begin{tabular}{c|c|c|c|c|c|c|c|c|c}
\hline \hline Distance & \multicolumn{3}{|c|}{100 g melamine } & \multicolumn{3}{c|}{300 g melamine } & \multicolumn{3}{c}{500 g melamine } \\
\hline R [cm] & Exp. & Cal. & RE & Exp. & Cal. & RE & Exp. & Cal. & RE \\
\hline 26.90 & 2.31849 & 2.35657 & 0.01642 & 2.34561 & 2.36618 & 0.00877 & 2.25491 & 2.35887 & 0.04610 \\
\hline 35.92 & 1.35641 & 1.28708 & 0.05111 & 1.41687 & 1.30709 & 0.07748 & 1.36399 & 1.30053 & 0.04653 \\
\hline 40.71 & 1.00000 & 1.00000 & 0.00000 & 1.00000 & 1.00000 & 0.00000 & 1.00000 & 1.00000 & 0.00000 \\
\hline 45.36 & 0.81117 & 0.80244 & 0.01077 & 0.80760 & 0.80815 & 0.00067 & 0.85946 & 0.81290 & 0.05418 \\
\hline 71.61 & 0.33607 & 0.32590 & 0.03024 & 0.34287 & 0.32651 & 0.04772 & 0.33230 & 0.32708 & 0.01572
\end{tabular}

Comparison of experimental and calculated absolute dose rates in $\mu \mathrm{Sv} / \mathrm{h}$.

TABLE VI

\begin{tabular}{c|c|c|c|c|c|c|c|c|c}
\hline \hline Distance & \multicolumn{3}{|c|}{ 100g melamine } & \multicolumn{3}{c|}{ 300g melamine } & \multicolumn{3}{c}{$500 \mathrm{~g}$ melamine } \\
\hline R $[\mathrm{cm}]$ & Exp. & Cal. & RE & Exp. & Cal. & RE & Exp. & Cal. & RE \\
\hline 26.90 & $3.82 \pm 0.382$ & $3.90 \pm 0.01$ & 0.0214 & $3.95 \pm 0.395$ & $4.01 \pm 0.015$ & 0.0165 & $4.09 \pm 0.409$ & $4.08 \pm 0.014$ & 0.0014 \\
\hline 35.92 & $2.23 \pm 0.223$ & $2.13 \pm 0.014$ & 0.0465 & $2.39 \pm 0.239$ & $2.22 \pm 0.014$ & 0.0704 & $2.47 \pm 0.247$ & $2.25 \pm 0.014$ & 0.0898 \\
\hline 40.71 & $1.65 \pm 0.165$ & $1.66 \pm 0.013$ & 0.0049 & $1.68 \pm 0.170$ & $1.69 \pm 0.013$ & 0.0076 & $1.81 \pm 0.181$ & $1.73 \pm 0.013$ & 0.0454 \\
\hline 45.36 & $1.34 \pm 0.134$ & $1.33 \pm 0.013$ & 0.0060 & $1.36 \pm 0.136$ & $1.37 \pm 0.013$ & 0.0083 & $1.56 \pm 0.156$ & $1.41 \pm 0.013$ & 0.0971 \\
\hline 71.61 & $0.55 \pm 0.055$ & $0.54 \pm 0.013$ & 0.0255 & $0.58 \pm 0.058$ & $0.55 \pm 0.013$ & 0.0404 & $0.60 \pm 0.060$ & $0.57 \pm 0.013$ & 0.0604
\end{tabular}

[10] G. Viesti, M. Cinausero, N. Cufaro-Petroni, G. D'Erasmo, D. Fabris, E. Fioretto, R. Fonte, M. Lunardon, I. Lazzizzera, G. Nardelli, G. Nardulli, G. Nebbia, M. Palomba, A. Pantaleo, L. Pappalardo, S. Pesente, P. Prati, G. Prete, S. Reito, A. Sartori, G. Tecchiolli, S. Zavatarelli, V. Filippini, Nucl. Instrum. Methods A 422, 918 (1999).
[11] T. Gozani, M. Elsalim, M. Ingle, E. Phillips, Nucl. Instrum. Methods A 505, 482 (2003).

[12] E.M.A. Hussein, M. Desrosiers, E.J. Waller, Rad. Phys. Chem. 73, 7 (2005).

[13] L.S. Waters, MCNPX User's Manual, Version 2.4.0, LA-CP-02-408, 2002. 